\title{
Development of Mobile Self-Monitoring Tool Prototype Based on User-Centered Design
}

\author{
https://doi.org/10.3991/ijet.v14i24.12043
}

Harry B. Santoso ${ }^{(凶)}$, Muhammad Luqman Hakim, Rahma Khairunisa Nursalamah, Panca O. Hadi Putra Universitas Indonesia, Jawa Barat, Indonesia harrybs@cs.ui.ac.id

\begin{abstract}
This study aims to develop a mobile application prototype for self-monitoring. Exercising self-regulated learning is considered as one of the ways that can help students achieve their learning goals. One of the key components of self-regulated learning is self-monitoring, in which students could monitor their learning process. To make students get used to monitoring skill, a web-based application called self-monitoring tool was developed. User research was carried out by evaluating the existing web-based application via an interview. Findings from the interview were analyzed and used as requirements to develop the mobile application. By taking into account usability components and design principles, an interactive prototype of a mobile self-monitoring tool was designed for both student and instructor roles.
\end{abstract}

Keywords-Self-regulated learning, self-monitoring, user research, interview, mobile self-monitoring tool

\section{Introduction}

To achieve the goals of learning, a person may have regulated the way they learn by themselves. Researchers have studied this behavior and referred to it as selfregulated learning. It is defined as someone's ability to understand and control his or her learning environments [1-2]. Academically, existing studies show that selfregulated learning could increase students' academic achievements [3-4].

Students who self-regulate their learning process are cognitively active in their learning [5]. Consequently, this enables them to have knowledge, skills, and dispositions to accomplish academic goals they set for themselves [5]. In order to achieve an optimal result from self-regulated learning, self-monitoring is one of the critical components that should be done [6].

Self-monitoring is beneficial in students' learning processes [7-8]. It essentially supports students' endeavor in self-regulating their learning process. It typically requires students to observe their behavior and record whether or not it was properly aligned to the target behavior they aim [9]. In other words, students initially should have goals in learning. During their learning process, they observe and record their learning activities to ensure they are on the right way to achieve those goals. 
Instead of doing it manually, a digital tool can help intervene self-monitoring practice in the learning process. Some tools have been developed to help students train self-monitoring and self-regulated learning skill $[1,10,11]$. Specifically, a tool developed by Lanqin et al. [3] helps increase the students' learning achievements and the ability to do self-regulated learning.

Furthermore, the Faculty of Computer Science Universitas Indonesia has also developed a tool for helping students do self-monitoring, called self-monitoring tool [10]. It allows instructors, lecturers, and teaching assistants, to give sequential prompts to students. Students need to do what they are prompted to, and the instructor will give feedback. As a result, this will help students to monitor their learning goals regularly.

With the advancement of technology, educational institutions have always been developing innovative learning methods. Mobile learning or m-Learning is one of them. M-Learning allows students to access learning resources in portable devices anytime and anywhere. Additionally, $\mathrm{m}$-Learning differentiates ways of learning. As a result, it potentially increases students' interaction and persistence in learning processes [12].

This study discusses the development of a mobile application prototype for selfmonitoring as a follow-through on a web-based application for self-monitoring [11]. The application prototype was created based on user-centered design processes. The existing web-based application was evaluated in terms of its usability to gather new requirements for mobile application.

\section{Relevant Literature Review}

\subsection{E-learning and M-learning}

E-Learning is a process of learning and teaching that involves the Internet and digital tools [13-14]. The implementation of e-Learning Can facilitate learning anytime and anywhere. E-Learning is more than just an online repository of learning materials. Student-centered learning paradigm should be used to enhance the effectiveness of eLearning implementation.

As mobile technology emerges, e-Learning adopts it and becomes mobile learning or m-Learning. The concept of m-Learning emerged after the invention of portable technologies, such as mobile phones, tablets, handheld computers, and notebooks [15]. M-Learning uses mobile technology or combined with other technology to allow studying wherever and whenever [16].

\subsection{Self-regulated learning and self-monitoring}

Self-regulated learning is one of the most important skills for students since it is also considered as a lifelong learning skill [3, 17]. Self-regulated learning is the ability to observe and control the learning environment [4]. 
Self-regulated students are students who are proactive in their learning and aware of their strengths and weaknesses [17]. In addition, they are students who are cognitively active in their learning [5]. In self-regulated learning, self-monitoring has an essential role. Monitoring will give the information about what matches and mismatches between students' standards and the representation of the information of each phase of self-regulated learning in students' memory [6].

There are two activities in self-monitoring, namely self-observation and selfrecording [9]. Self-observation is the practice of someone doing an observation of their behavior. On the other hand, self-recording is the practice of someone record their self-observation. In other words, self-monitoring typically requires students to self-observe their behavior and self-record whether or not they engaged in the targeted behavior [9].

Self-monitoring can help students recognize and watch their behavior. By doing self-monitoring, students can identify and increase positive behavior that are needed in order to achieve successful education [18]. Furthermore, helping students monitor their work to accomplish their learning goals can train students to do self-regulation [19].

Self-monitoring could be a useful method for students at any level of education. It can be learned by all people with different cognitive level. Additionally, selfmonitoring intervention in the learning process is a flexible, effective, yet worth way among many other ways for students who have difficulties in academic and behaving [20]. There are five ways to do self-monitoring intervention for students [18]:

1. Identify the behavior of the students

2. Select/design the system for self-monitoring

3. Choose reinforcers and how students will earn them

4. Teach students to use the system

5. Lessen intervention from the role of adults

To facilitate self-monitoring, Faculty of Computer Science Universitas Indonesia developed a tool called self-monitoring tool [11]. It is a web-based application which is expected to help students monitor their learning goals. There are two primary users in this tool which are a lecturer or teaching assistant as instructor and student. Instructors can give sequential prompts. Meanwhile, students are supposed to do what they are prompted to and receive personal feedback from instructors afterward. The difference between the tool compared to other tools is not only in terms of its use for weekly context, but can also be implemented to support the use of learning management systems in the faculty.

\subsection{E-learning and self-monitoring}

The self-monitoring tool is a part of an e-Learning system. In order to enable selfmonitoring, the system provides a set of prompts. It is also expected to motivate students to achieve their learning goals.

A prompt is an instructive method used to guide students [3, 10]. It can be delivered in various formats, such as a simple question, incomplete sentence, instruction 
execution, and picture or graph [3]. It is also an approach to help students recall their knowledge and encourage them to get new knowledge [10]. In an online learning environment, a combination of prompt and corrective feedback can help students in problem-solving and knowledge acquisition [21].

\section{$3 \quad$ Methodology}

\subsection{Participants}

This study involved 23 participants comprising ten students, five teaching assistants, and eight lecturers (see Table 1). All participants have experiences in using learning management systems. Specifically, the lecturers involved in the study are the leading lecturers or 'champions' regarding the use of online learning in their institution. The researchers expected that they could provide insightful comments. They were chosen conveniently based on the role they represented respectively. Students represent the student role in the system. In addition, teaching assistants and lecturers represent the instructor role in the system. User-Centered Design (UCD) method was used to capture the respondents' perspectives, needs and expectations. The method is also quite dynamic to guide the prototype development process [22].

Table 1. List of Participants

\begin{tabular}{|l|c|l|}
\hline \multicolumn{1}{|c|}{ Participant } & Total & \multicolumn{1}{c|}{ Institution } \\
\hline Student & 10 & Faculty of Computer Science, Universitas Indonesia \\
\hline Teaching Assistant & 5 & Faculty of Computer Science, Universitas Indonesia \\
\hline \multirow{4}{*}{ Lecturer } & 4 & Faculty of Computer Science, Universitas Indonesia \\
\cline { 2 - 3 } & 1 & Faculty of Cultural Science, Universitas Indonesia \\
\cline { 2 - 3 } & 1 & Faculty of Nursing, Universitas Indonesia \\
\cline { 2 - 3 } & 1 & Faculty of Social Science, Universitas Indonesia \\
\cline { 2 - 3 } & 1 & Faculty of Mathematics and Science, Universitas Padjadjaran \\
\hline
\end{tabular}

\subsection{Data collection}

Data were collected in April and May 2017 by means of a semi-structured interview. The interview was conducted to figure out problems, find alternative solutions, and get other feedback about the existing system. The instruments of the interview consisted of both open-ended and close-ended questions. To be able to obtain reliable insights, all participants were asked to explore the existing system before the interview.

\subsection{Data analysis}

The whole processes of data analysis are illustrated in Figure 1. User research was conducted by interviewing users. Collected data from the interview were analyzed to get user requirements. They were grouped into three categories, namely usability 
problems and solutions, other user interface improvements, and new features. Findings were considered as usability problems if they affected the five components of usability [23], i.e., learnability, efficiency, memorability, errors and satisfaction. It is important to consider usability as it would show how an interface could support its users in achieving their goals [24-25].

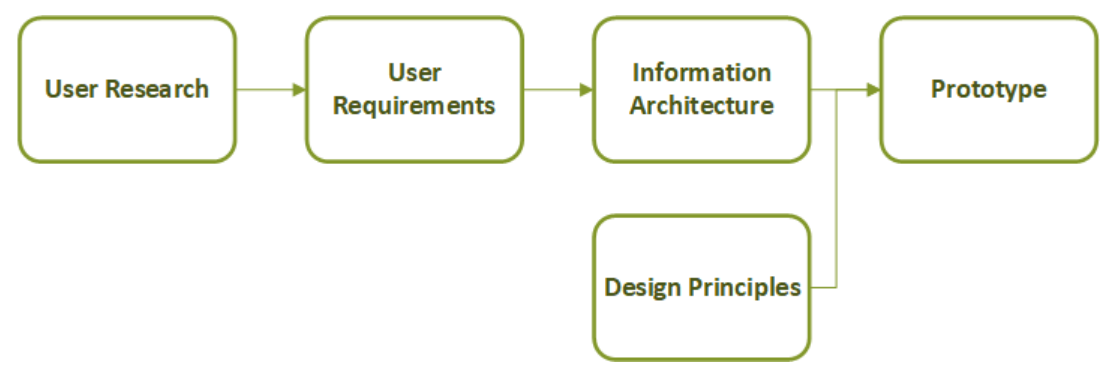

Fig. 1. Analysis Process

After getting new user requirements, new information architecture was redesigned. It helped to see a big picture of what activities or tasks user can do in the new system. Hence, it supported the creation of the prototype later.

\subsection{Prototype design}

Based on the requirements gathered, an interactive and high-fidelity prototype was designed. This type of prototype was chosen to provoke realistic interaction and reliable feedback. Other than user requirements, Shneiderman's Eight Golden Rules, one of the most popular design principles, were applied in the making of the prototype to ensure the quality of its experience. The final version of the prototype was delivered through an online prototyping tool called Marvelapp (https://marvelapp.com).

\section{$4 \quad$ Results}

\subsection{Results for the student role}

User problems and solutions. Ten participants said that the system is quite easy to use. They only encountered minor difficulty. Table 2 shows the problem and the solution as suggested by participants.

Table 2. Problems and solutions: the student role

\begin{tabular}{|l|l|l|}
\hline No. & \multicolumn{1}{|c|}{ User Problem } & \multicolumn{1}{c|}{ Suggested Solution } \\
\hline 1 & $\begin{array}{l}\text { Unable to differentiate unanswered and an- } \\
\text { swered prompts (2 participants) }\end{array}$ & $\begin{array}{l}\text { Differentiate unanswered and answered prompts by } \\
\text { giving tick or using different color }\end{array}$ \\
\hline
\end{tabular}


Other feedback. Table 3 shows other improvements in user interface design suggested by participants

Table 3. Suggested user interface improvements: the student role

\begin{tabular}{|c|l|}
\hline No. & \multicolumn{1}{|c|}{ Suggested Improvements } \\
\hline 1 & Differentiate non-answered prompts and answered prompts (3 participants) \\
\hline 2 & Improve prompt list page due to no separation between prompts (4 participants) \\
\hline 3 & Make the list of prompts looked clickable (4 participants) \\
\hline 4 & Pay attention to the order of prompts in prompt list page (2 participants) \\
\hline 5 & Group prompts in prompt list page (2 participants) \\
\hline 6 & Show keywords in prompt list page (1 participant) \\
\hline 7 & Change the term 'prompt' (1 participant) \\
\hline 8 & Change font type (1 participant) \\
\hline
\end{tabular}

Table 4 shows new features as suggested by participants.

Table 4. Suggested new features: the student role

\begin{tabular}{|c|l|}
\hline No. & \multicolumn{1}{|c|}{ Suggested Features } \\
\hline 1 & Notification feature (4 participants) \\
\hline 2 & Support other inputs, not only text (4 participants) \\
\hline 3 & Provide correction result on answered prompts (1 participant) \\
\hline 4 & A simple feature to tell instructor for prompts that are not grasped by a student (1 participant) \\
\hline 5 & Pin/bookmark prompt feature (1 participant) \\
\hline 6 & $\begin{array}{l}\text { Combine classes from different instructors so that students can access classes from other instruc- } \\
\text { tors (1 participant) }\end{array}$ \\
\hline 7 & Provide the solution/answer key of prompts (1 participant) \\
\hline 8 & Provide instructor's contact (1 participant) \\
\hline
\end{tabular}

\subsection{Results for the instructor role}

User problems and solutions. Six out of 13 participants said that the system is quite easy to use. However, participants still found some difficulties. The difficulties can be grouped into several themes: inefficiency dealing with prompts; difficulty in looking at the students' status; and difficulty in providing feedback. Table 5 shows the problems and solutions suggested by participants.

Table 5. Problems and solutions: the instructor role

\begin{tabular}{|c|l|l|}
\hline No. & \multicolumn{1}{|c|}{ User Problems } & \multicolumn{1}{|c|}{ Suggested Solutions } \\
\hline 1 & Difficult to create new prompt (5 participants) & $\begin{array}{l}\text { Show required fields in the new prompt } \\
\text { form, handle any errors and view prompt } \\
\text { after created }\end{array}$ \\
\hline 2 & $\begin{array}{l}\text { It is a time-consuming task to open students' answers } \\
\text { one by one (3 participants) }\end{array}$ & Show all students' answers on one page \\
\hline 3 & $\begin{array}{l}\text { Prompts in prompt list page seems unclickable and the } \\
\text { list is too long (2 participants) }\end{array}$ & $\begin{array}{l}\text { Group prompts and make them seem } \\
\text { clickable }\end{array}$ \\
\hline 4 & $\begin{array}{l}\text { Cannot differentiate read and unread students' answers } \\
\text { (1 participant) }\end{array}$ & $\begin{array}{l}\text { Differentiate read and unread students' } \\
\text { answers }\end{array}$ \\
\hline
\end{tabular}




\begin{tabular}{|c|l|l|}
\hline 5 & $\begin{array}{l}\text { Giving other feedback feature is not efficient (1 partici- } \\
\text { pant) }\end{array}$ & $\begin{array}{l}\text { Giving feedback feature is in one field } \\
\text { and provide feedback recommendation } \\
\text { feature }\end{array}$ \\
\hline 6 & Expand button is not working (1 participant) & $\begin{array}{l}\text { Change/remove the icon (It is not an } \\
\text { expand button) }\end{array}$ \\
\hline 7 & Term 'prompt' is not familiar (1 participant) & $\begin{array}{l}\text { Change terms in the system with the } \\
\text { familiar one }\end{array}$ \\
\hline 8 & Guide menu disappears when logged in (1 participant) & Always show guide menu \\
\hline
\end{tabular}

Other feedback. Table 6 shows other improvements in user interface design suggested by participants.

Table 6. Suggested user interface improvements: the instructor role

\begin{tabular}{|c|l|}
\hline No. & \multicolumn{1}{|c|}{ Suggested Improvements } \\
\hline 1 & Provide confirmation box before deleting prompt (1 participant) \\
\hline 2 & Provide a sign that there are more contents on the bottom of the homepage (1 participant) \\
\hline 3 & Provide right information on the browser tab title (1 participant) \\
\hline
\end{tabular}

Table 7 shows new features suggested by participants.

Table 7. Suggested new features: the instructor role

\begin{tabular}{|c|l|}
\hline No. & \multicolumn{1}{|c|}{ Suggested Features } \\
\hline 1 & Provide student report or achievements (8 participants) \\
\hline 2 & Support other inputs, not only text (4 participants) \\
\hline 3 & Notification feature (4 participants) \\
\hline 4 & Support other question types, not only essay (2 participants) \\
\hline 5 & Put something that will encourage students to use system (1 participant) \\
\hline 6 & Integrate with an existing learning management system if any (1 participant) \\
\hline 7 & Give feedback to several students in one time to save time (1 participant) \\
\hline 8 & Provide a scoring system on students' answers (1 participant) \\
\hline 9 & Correct students' answers using machine learning (1 participant) \\
\hline
\end{tabular}

\subsection{Information architecture}

Based on user requirements, information architecture for mobile self-monitoring tool was designed. While information architecture for the student role is illustrated in Figure and 2, information architecture for the instructor role is shown in Figure 3. 


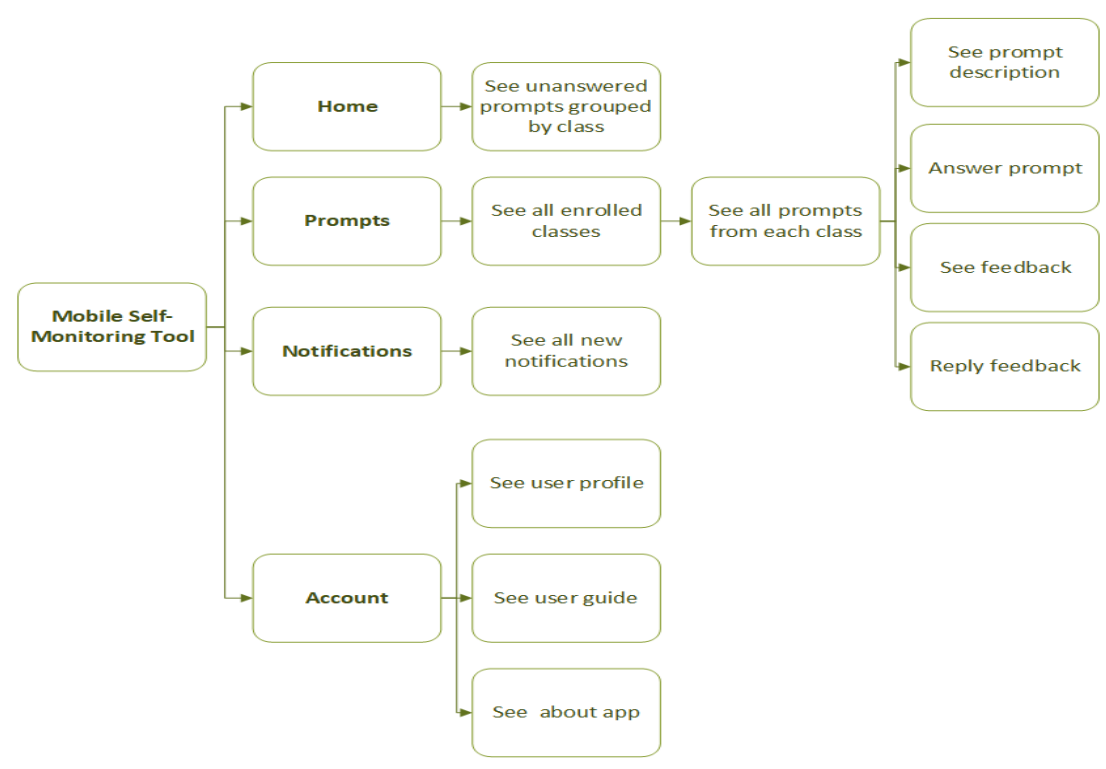

Fig. 2. Information architecture: the student role

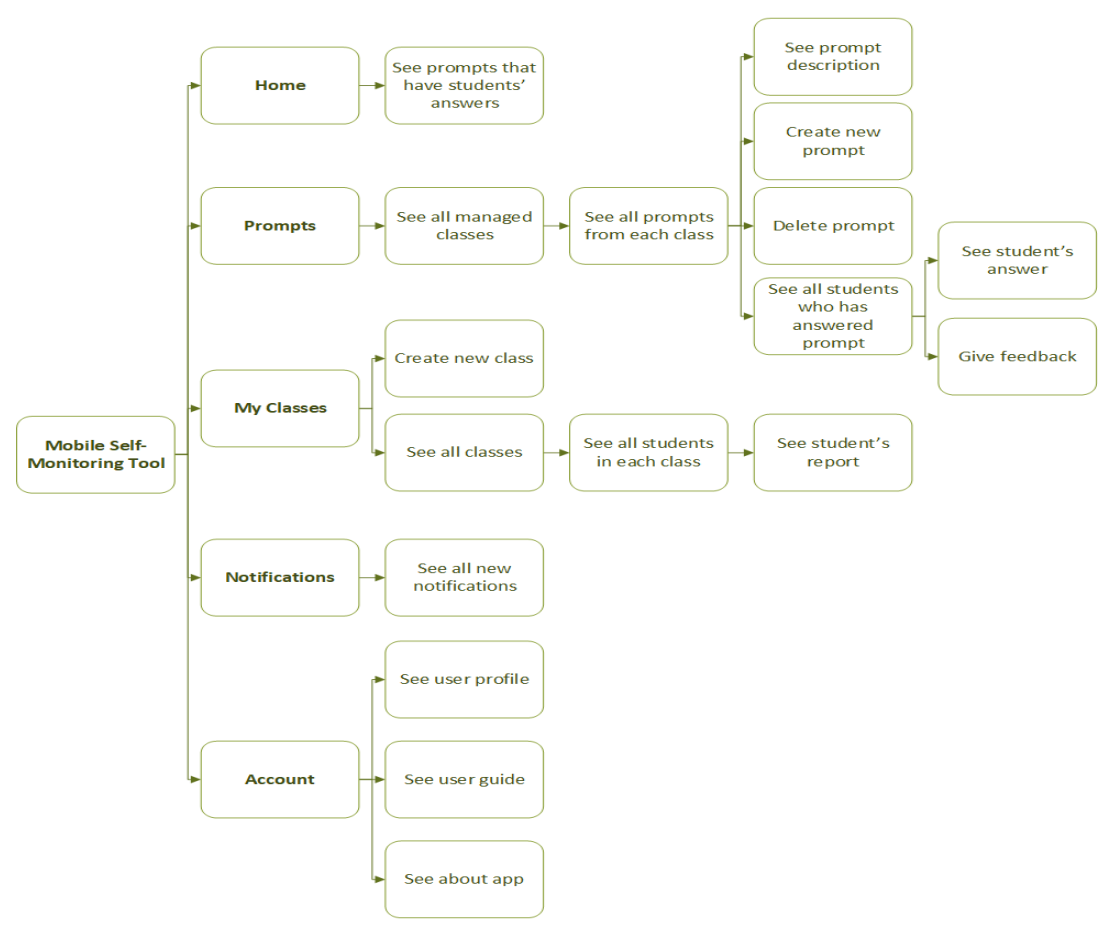

Fig. 3. Information architecture: the instructor role 


\subsection{Prototype design}

This section explains the prototype of mobile self-monitoring tool. Some prototype interfaces are shown below for each role.

The prototype for the student role. Figure 4 shows the home page, which displays unanswered prompts that grouped by class. It is the first page displayed when students open this application. It gives a shortcut to find and visit the page of the main task students do in this application, which is answering prompts. It follows one of Shneiderman's Rules, enabling frequent users to use shortcuts.

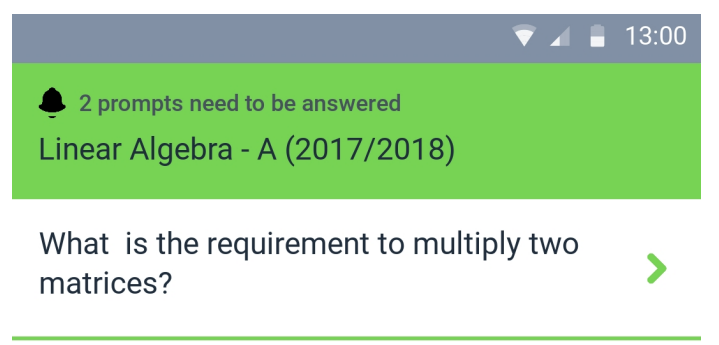

What are types of linear transformation >

2 prompts need to be answered

Calculus - B (2017/2018)

How many types of numbers do you know? What are they?

What is differential? And what is integral?

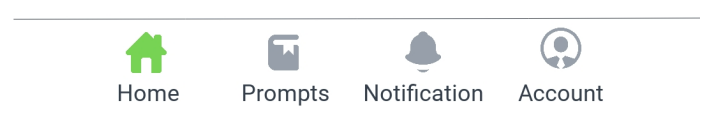

Fig. 4. Home page: the student role

Figure 5 shows the answer prompt page, which allows students to see and answer prompt. They can input text and image. If they tap prompt, it shows the detail of the prompt. 

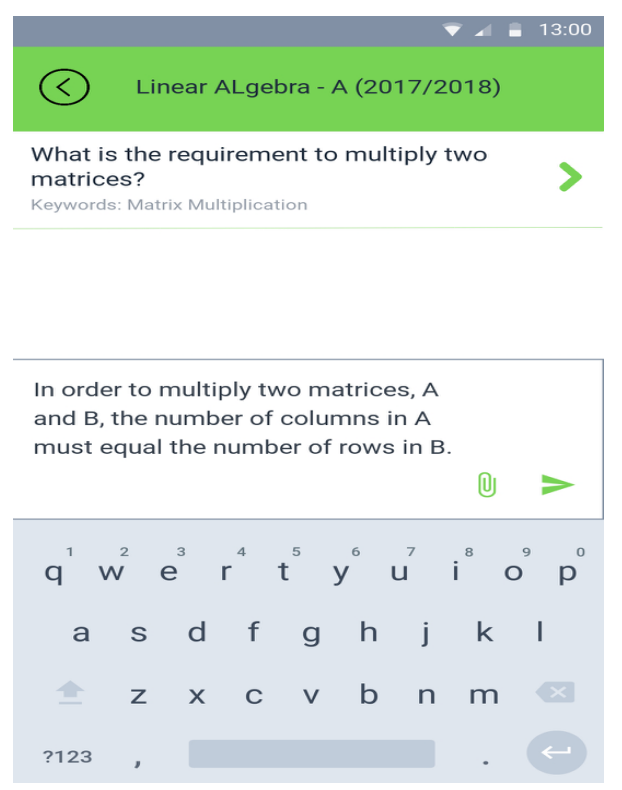

Fig. 5. Answer prompt page: the student role

The prototype for the instructor role. Figure 6 shows the home page, which displays answered prompts by students. It is the first page displayed when instructors open this application. It gives a shortcut to find and visit the page of the main task instructors do in this application, which gives feedback on students' answers. It follows one of Shneiderman's Rules, enabling frequent users to use shortcuts.
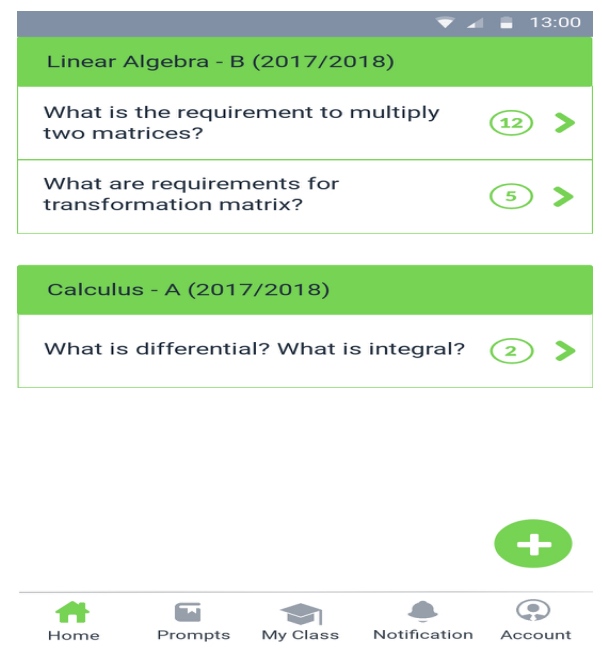

Fig. 6. Home page: the instructor role 
Figure 7 shows a prompt's answers list page, which displays a list of students who have answered a certain prompt. It is sorted by time, and the latest is at the top. If the list has been visited or tapped, its background color becomes darker. It follows one of Shneiderman's Rules, reducing short-term memory load.

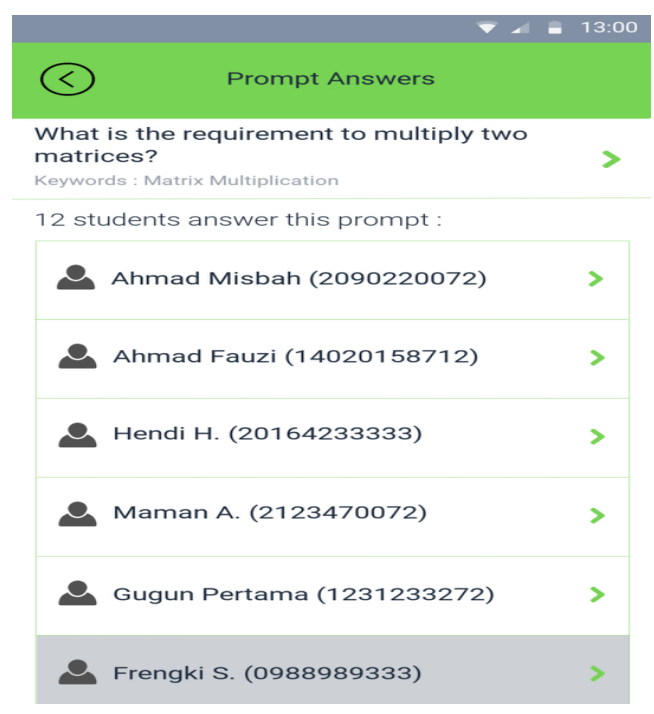

Fig. 7. Prompt's answer list page: the instructor role

Figure 8 shows a prompt's answer page, which allows instructors to see student's answer and give feedback. Instructors can input text or image. If they tap prompt, it will show the detail of the prompt.

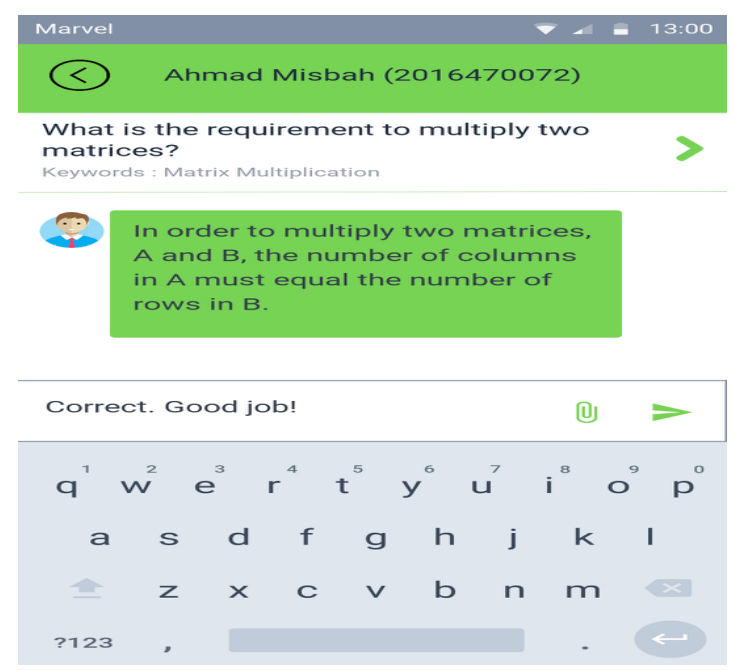

Fig. 8. Prompt's answer page: the instructor role 


\section{Conclusion}

This study aims to design the prototype of mobile self-monitoring tool. The usercentered design was applied in the process. An evaluation was done to the existing web-based self-monitoring tool in terms of its usability. The result was categorized into several types of user requirements. These requirements were then used to support the development of a mobile application prototype.

From the result of user research, 16 out of 23 participants said that the tool is relatively easy to use. However, some improvements are needed to be done. Most students were concerned about their interaction with the prompts while instructors found the reporting system could be refined. The existing website design was translated into an interactive mobile application prototype based on user requirements and design principles.

\section{References}

[1] Ifenthaler, D. "Determining the effectiveness of prompts for self-regulated learning in problem-solving scenarios." Educational Technology \& Society, 15(1), pp. 38-52. 2012.

[2] Schraw, G., Crippen, K. J., \& Hartley, K. "Promoting self-regulation in science education: Metacognition as part of a broader perspective on learning." Research in Science Education, 36, pp. 111-139. 2006. https://doi.org/10.1007/s11165-005-3917-8

[3] Lanqin, Z., Xin, L., \& Fengying, C. "Effects of a mobile self-regulated learning approach on students' learning achievements and self-regulated learning skills." Innovations in Education and Teaching International, pp. 1-9. 2016. https://doi.org/10.1080/14703297.2016.1 $\underline{259080}$

[4] Sun, Z., Xie, K., \& Anderman, L. H. "The role of self-regulated learning in students' success in flipped undergraduate math courses." The Internet and Higher Education. Vol. 36, pp. 41-53. 2018. https://doi.org/10.1016/j.iheduc.2017.09.003

[5] Bell, C. V., \& Pape, S. J. "Scaffolding the development of self-regulated learning in mathematics classrooms." Middle School Journal, 45(4), pp. 23-32. 2014.

[6] Anson, W. (2004). "Effects of teaching self-monitoring in a distance learning course." [Online]. Available: ProQuest Information and Learning Company [Jan 20, 2019]

[7] Guderjahn, L., Gold, A., Stadler, G., \& Gawrilow, C. "Self-regulation strategies support children with ADHD to overcome symptom-related behavior in the classroom." $A D H D A t-$ tention Deficit and Hyperactivity Disorders, 5(4), pp. 397-407. 2013. https://doi.org/10.10 07/s12402-013-0117-7

[8] Mooney, P., Ryan, J. B., Uhing, B. M., Reid, R., \& Epstein, M. H. "A review of selfmanagement interventions targeting academic outcomes for students with emotional and behavioral disorders." Journal of Behavioral Education, 14(3), pp. 203-221. 2005. https:// doi.org/10.1007/s10864-005-6298-1

[9] Rafferty, L. A. "Step-by-step: teaching students to self-monitor." TEACHING Exceptional Children, 43(2), pp. 50-58. 2010. https://doi.org/10.1177/004005991004300205

[10] Bannert, M., \& Reimann, P. "Supporting self-regulated hypermedia learning through prompts." Instructional Science, 40, pp. 193-211. 2012. https://doi.org/10.1007/s11251$\underline{011-9167-4}$ 
[11] Santoso, H. B., Nurrohmah, I., Fadhilah, S., \& Goodridge, W. H. "Evaluating and redsigning the self-monitoring tool. International Journal on Advanced Science." Engineering and Information Technology, 7(1), pp. 228-234. 2017. https://doi.org/10.18517/ijaseit.7.1.1526

[12] Göksu, İ., \& Atici, B. "Need for mobile learning: Technologies and opportunities." Procedia-Social and Behavioral Sciences, 103, pp. 685-694. 2013. https://doi.org/10.1016/j.sbs pro.2013.10.388

[13] Arkorful, V., \& Abaidoo, N. "The role of e-learning, the advantages and disadvantages of its adoption in higher education." International Journal of Education and Research, 2(12), pp. 397-410. 2014.

[14] Whale, A., Scholtz, B., \& Calitz, A. "Classification of heuristics for components of eLearning." South African Institute of Computer Scientists and Information Technologists, pp. 1-15. 2015. https://doi.org/10.1145/2815782.2815794

[15] Alkhalifah, T., Vries, D. d., \& Rampersad, G. "Mobile Learning Adoption in Developing Countries." 9th International Conference on Education Technology and Computers, pp. 89-93. 2017. https://doi.org/10.1145/3175536.3175583

[16] Xiao, J. "Application of mobile learning system in phonetics teaching." 8th International Conference on E-Education, E-Business, E-Management and E-Learning, pp. 19-23. 2017.

[17] Zimmerman, B. J. "Becoming a self-regulated learner: An overview." Theory Into Practice, 41(2), pp. 64-70. 2002. https://doi.org/10.1207/s15430421tip4102 2

[18] Loftin, R. L., Gibb, A. C., \& Skiba, R. "Using self-monitoring strategies to address," in Fostering Success in School and Beyond for Students with Emotional/Behavioral Disorders, 18(2), pp. 12-13. 2005.

[19] Schunk, D. H. "Inherent details of self-regulated learning include student perceptions." Educational Psychologist, 30(4), pp. 213-216. 1995. https://doi.org/10.1207/s15326985ep3 $\underline{0047}$

[20] Mitchem, K. J., Young, K. R., West, R. P., \& Benyo, J. "CWPASM: A classwide peerassisted self-management program for general education classrooms." Education and Treatment of Children, 24(2), pp. 111-140. 2001

[21] Huang, K., Chen, C.-H., Wu, W.-S., \& Chen, W.-Y. "Interactivity of question prompts and feedback on secondary students' science knowledge." Journal of Educational Technology \& Society, 18(4), pp159-171. 2015.

[22] Preece, J., Rogers, Y., \& Sharp, H. "Interaction design: Beyond human-computer interaction (4th ed)." Chichester: John Wiley \& Sons. 2015.

[23] Nielsen, J. (2012, January 4). Usability 101: Introduction to Usability. [Online]. Available: https://www.nngroup.com/articles/usability-101-introduction-to-usability/ [Jan 20, 2019]

[24] Haaksma, T. R., Jong, M. D., \& Karreman, J. "Users' personal conceptions of usability and user experience of electronic and software products." IEEE Transactions on Professional Communication, 61(2), pp. 116-132. 2018. https://doi.org/10.1109/tpc.2018.279539 $\underline{8}$

[25] Sitorus, H. M., Govindaraju, R., Wiratmadja, I. I., \& Sudirman, I. "Interaction perspective in mobile banking adoption: The role of usability and compatibility." International Conference on Data and Software Engineering (ICoDSE), pp. 1-6. 2017. https://doi.org/10.11 09/icodse.2017.8285878

\section{$7 \quad$ Authors}

Harry Budi Santoso, PhD is a faculty member at the Faculty of Computer Science in Universitas Indonesia (UI). He received his BS and MS in Computer Science from 
Universitas Indonesia (UI), and his PhD from the Department of Engineering Education at Utah State University, in the USA.

He teaches several courses at UI (e.g., computer-assisted instruction, computer and society, human-computer interaction). He is also the Head of the Digital Library and Distance Learning Laboratory. His research.interests include personalized learning, metacognition, user experience and online distance learning.

Muhammad Luqman Hakim is a founder of Pintaar (pintaar.com), a skill-based online learning platform. It helps students in Indonesia to learn from professionals through videos. He received his BS in Computer Science from Universitas Indonesia (UI). He was a research assistant in the Digital Library and Distance Learning Laboratory. His interests includes online education, course development, and user experience.

Rahma Khairunisa Nursalamah is a bachelor in computer science from Universitas Indonesia (UI). She is a Senior User Experience (UX) Researcher at Halodoc, where she conducts studies to simplify healthcare in Indonesia. She has taught UX Design at Purwadhika Startup School and tutored Web Design and Programming at UI. She was also a research assistant at the Digital Library and Distance Learning Laboratory. Her current research interests include mobile health, teleconsultation, metacognition and user experience.

Panca O. Hadi Putra is a lecturer at the Faculty of Computer Science, Universitas Indonesia. He holds a B.Sc with honors in information systems from Sunway University, an M.Bus in business and information systems from College of Business and Economics, the Australian National University, and a Ph.D in computer science from the Faculty of Computer Science, Universitas Indonesia. Dr. Putra teaches both graduate and undergraduate courses, including systems analysis and design, enterprises systems, and e-commerce. His research interests are in the areas of design science in information systems, user experience, and digital learning.

Article submitted 2019-09-27. Resubmitted 2019-10-25. Final acceptance 2019-11-05. Final version published as submitted by the authors. 